\title{
Presença cultural francesa no Brasil
}

\author{
Marcio Rodrigues Pereira*
}

\section{Raízes históricas}

A presença da cultura francesa no Brasil se desenvolve no século XIX. Antes, existem apenas vestígios de uma França que, por algumas vezes, tenta ocupar a colônia portuguesa do Novo Mundo, ou ao menos parte dela - como na tentativa, em meados do século XVI, de criação da França Antárctica, onde a posteriori é fundada a cidade de São Sebastião do Rio de Janeiro; antes batizada pelos franceses como Henriville.

Esse primeiro infortúnio dos franceses não os impede de continuar insistindo. Em 1590, eles buscam se estabelecer em Viçosa, no Ceará. Entre 1612 e 1615, fundam a França Equinocial, a partir da cidade que nomeiam de Saint Louis, futura São Luís do Maranhão. São novamente expulsos pelos portugueses, restando-lhes, por fim, no continente sul-americano, a Guiana Francesa.

Como se observa, as frustradas tentativas dos colonizadores franceses nos privou de desenvolvermos uma cultura diretamente entrelaçada à deles. Como o fluxo migratório francês em direção ao Brasil sempre fora irrelevante e as relações comerciais entre os dois países pouco importantes (apesar de não negligenciáveis), podemos afirmar que as razões da influência preponderante - em relação às demais culturas europeias, exceto, evidentemente, a portuguesa - da cultura francesa sobre a elite brasileira não podem ser explicadas nem pela migração, nem pela relação comercial (ROLLAND, 2000b).

* Marcio Rodrigues Pereira / Mestrado (DEA) em História Contemporânea, Université Paris 4-Sorbonne; doutorado em História Contemporânea, Université de Strasbourg 3. Ex-professor na Universidade Cândido Mendes, Rio de Janeiro.

PS: Todas as citações foram traduzidas por mim. 
Mas, tal preponderância também não pode ser explicada por nenhuma crença ou retórica que possa vir a justificar a ideia de que a cultura francesa represente alguma espécie de particularismo superior às demais culturas europeias, também presentes na América Latina no século XIX. Por outro lado, devemos nos deter ao fato de que a influência preponderante da cultura da França sobre a elite brasileira está diretamente ligada à dinâmica do capitalismo, ou seja, à mobilização do capital e do comércio no espaço geográfico e temporal (BRAUDEL, 1987).

A França, como outros impérios europeus do século XIX, disputava terras e comércio; em resumo, riqueza e poder no continente americano. A partir do último decênio do século XVIII, todo o continente latino-americano passa a viver uma forte ebulição, que conduz à independência e à consequente criação dos novos Estados nacionais na região. Para a França, como grande potência imperial, a independência das colônias espanholas e portuguesa significa antes de tudo um ganho (sem falar da América do Norte, onde os franceses lutam, entre 1776 e 1883, ao lado dos americanos pela independência, contrariando, assim, os interesses da sua maior concorrente, a Inglaterra). Certamente, esses novos Estados, livres do constrangimento do sistema colonial, e particularmente do monopólio metropolitano, podem passar a comercializar diretamente com a França; ao menos em teoria, já que na América Latina, economicamente falando, o império inglês torna-se o principal favorecido.

No que concerne aos aspectos políticos e ideológicos, a procura de paradigmas passíveis de alimentar as lutas de independência leva os chefes libertadores da América Latina a se inspirarem na filosofia lluminista, na Revolução Francesa e na guerra de independência dos Estados Unidos; ou seja, boa parte do que, nesse período, fustiga a consciência pela independência e luta pela liberdade relacionase direta e indiretamente à França e à sua cultura, particularmente literária. Além disso, podemos ainda acrescentar a invasão napoleônica sobre a Península Ibérica, no primeiro decênio do século XIX, como uma ação que enfraquece consideravelmente as coroas portuguesa e espanhola e acaba, indiretamente, por reforçar as lutas pela independência na América Latina - lutas dirigidas, cabe novamente enfatizar, contra os impérios atacados pelas armas francesas na Península Ibérica.

Assim sendo, a influência preponderante da cultura francesa na consciência das elites do Brasil e da América Latina em geral explica-se a partir da constatação de um contexto histórico-social favorável à França: enquanto a França participa direta e/ou indiretamente nas lutas pela independência na América Latina, a Inglaterra, noutro fronte, luta desde 1776 para conservar suas colônias na América do Norte, e, se nos limitarmos somente ao Brasil, também protege a transferência da corte de Lisboa para o Rio de Janeiro, em 1808.

Consequentemente, dentre os impérios que disputam o continente americano, somente a França poderia despertar simpatia e admiração. Ao contrário, Inglaterra, Espanha e Portugal, por razões evidentes, são percebidos como inimigos da liberdade e da independência. 
No Brasil pós-independência, ficou gravada na consciência da elite a imagem da França como "farol» da Liberdade, Igualdade e Fraternidade, da filosofia Iluminista, que apesar de por vezes coagir ideologicamente a monarquia e mesmo a Primeira República, continua sendo a principal matriz ideológica na formação dos republicanos, sem falar, curiosamente, nos monarquistas - uma vez que republicanos e monarquistas aos quais faço alusão confundem-se em uma mesma elite econômica e política.

Essa matriz ideológica ligada à cultura francesa alimenta os espíritos de boa parte da intelligentsia brasileira, assim como a historiografia que contribuira para o mito da "grande França», e sua "grande cultura». Enquanto consequência lógica, tal imagem positiva incita a elite brasileira a convidar intelectuais e artistas franceses a contribuir para a criação de várias instituições no país; sendo que, mais tarde, já no século $X X$, intelectuais e artistas franceses passam a ser subvencionados e instrumentalizados pelo Estado francês, através da sua política cultural exterior, e, com isso, começam a participar amplamente das pesquisas destinadas a compreender e descrever o Brasil e sua cultura, sendo, então, integrados à intelligentsia que pensa o Brasil. Consequentemente, boa parte dos intelectuais brasileiros passa a ver o Brasil a partir de uma ótica parcialmente francesa, colaborando, portanto, para o status quo da preponderância cultural da França no país, ao menos até a década de 1960.

\section{A França agrada a todos os matizes ideológicos}

Falta explicar o porquê da preponderância da cultura francesa, entre os mais diversos matizes ideológicos que compõem a elite brasileira do século XIX.

Como nos ensina Norbert Elias, o conceito de «civilidade» se aprimora na nobreza de corte francesa, desde o século XVII. Ele se caracteriza pelas «convenções de estilo, pela educação da sensibilidade, pela importância atribuída à cortesia, pelo belo linguajar e pela arte da conversação» (ELIAS, 1973, p. 63) ; ou seja, pelos aspectos humanos superficiais, que exatamente por serem superficiais, são mais fáceis de ser adotados e percebidos.

No decorrer do século XVIII, à medida que parte da burguesia francesa enriquece, a nobreza de corte passa a assimilá-la, ocorrendo, nesse processo, uma espécie de simbiose, particularmente francesa, entre a nobreza de corte e a alta burguesia, que faz com que esta última adquira os hábitos da «civilidade». Sendo a França um país bastante centralizado, desde o século XVII, Paris passará a reunir a riqueza e a intelligentsia intelectual e artística oriundas tanto da aristocracia quanto da burguesia nacional, bem como a atrair as demais nobrezas de corte e intelligentsias europeias.

Como o pensamento e os hábitos de "civilidade» da corte francesa são desvinculados grosso modo da realidade social nos espaços geográficos (inclusive, do próprio território francês), em função de sua superficialidade, já que são centrados nos aspectos humanos externos, eles puderam ser adotados pelas 
mais diversas nobrezas de corte da Europa, inclusive a de Lisboa - assim sendo, a transferência da corte lisboeta para o Rio de Janeiro em 1808 é também a transferência e afirmação do conceito de "civilidade» à la française.

Portanto, independentemente das divergências ideológicas no interior da elite brasileira, os elementos culturais oriundos da França, principalmente aqueles a reboque de hábitos comportamentais superficiais, ligados à ideia de «civilidade», podem agradar revolucionários em luta pela independência (final do século XVIII e início do XIX), monarquistas e mesmo membros expulsos da corte de Portugal pelas tropas francesas (!), republicanos (que ascendem ao poder em 1889), sejam escravagistas ou não.

\section{Momentos relevantes da presença cultural da França no Brasil do século $\mathrm{XIX}$}

Vemos que, desde o fim do século XVIII, os elementos culturais originários da França (maneira de se comportar, filosofia, literatura, artes, etc.) reúnem as vantagens necessárias para serem os preferidos pela elite brasileira. Os iluministas inspiram a Inconfidência Mineira, em 1789. Em 1816, por desejo de Dom João $\mathrm{VI}$, a influência francesa se faz através das artes, da arquitetura, da engenharia e das técnicas de manufaturas com a chegada dos dezesseis membros da missão francesa, encarregados de inaugurar no Brasil a sistematização do ensino das artes e das técnicas de manufaturas, com a inauguração em 1826 da Academia Imperial de Belas Artes. A partir do Segundo Reinado, em meados do século XIX, a relação brasileira com a cultura francesa torna-se ainda mais estreita. Nessa época, a elite brasileira já adquirira o hábito de viajar para a França, buscando ter a sua formação embasada na cultura do país. Durante o reinado de Dom Pedro II, desenvolve-se a tradição - iniciada por Dom João VI - de convidar franceses ilustres para dirigir a criação de instituições de ensino no Brasil, como é o caso do cientista Emmanuel Lias, que assume a direção do Observatório Nacional, e também de Garceix, que é um dos fundadores da Escola de Minas de Ouro Preto, sem contar que o Ministério da Educação nacional impõe o idioma francês como segunda língua no Brasil, "pelo número de ilustres professores e pela norma de serem adotados, nos estudos, os livros vindos da França, vendidos nas grandes livrarias do Rio e São Paulo» (TAVARES, 1979, p. 229).

A filosofia positivista, apreciada no Brasil desde os anos de 1840, desenvolvese no decorrer da década de 1870 , e tem grande influência sobre os republicanos brasileiros. Por isso, é o pensamento de um francês que sela não somente a nossa primeira Constituição republicana, mas também a divisa da bandeira nacional, com Ordem e Progresso (ideia expressa por Augusto Comte, em 1848, em Paris, na circular que divulga a criação da Société Positiviste (ROBINET, 1864, p. 439).

Durante o último terço do século XIX e início do século XX, a influência cultural francesa é tanta que por vezes se manifesta de maneira um pouco caricata. A Academia Brasileira de Letras, criada em 1897, além de instalada no Petit 
Trianon carioca, em 1923 (prédio construído pelos franceses em homenagem ao centenário da Independência do Brasil, e réplica do Petit Trianon, de Versailles), reproduz quase que identicamente, desde a sua fundação, várias características da Academia Francesa: o número de cadeiras (40), o sistema de eleição, os chás que precedem as sessões, a indumentária (igual ao habit vert francês, etc.). Tais exageros despertam a atenção até mesmo de estrangeiros, como é o caso do escritor austríaco Stefan Zweig, exilado no Brasil durante a Segunda Guerra, e que diz que «tudo o que é francês age como um estimulante sobre os parlamentares brasileiros [...] e a cópia de tudo o que é francês vai tão longe que dois políticos brasileiros tomaram ridiculamente os nomes de Lafayette e Benjamin Constant»" (ZWEIG, 1992, p. 92).

\section{Política cultural internacional francesa}

No século XIX, em decorrência do crescimento industrial e o consequente aumento da concorrência pela expansão comercial entre as nações, desenvolvemse os nacionalismos europeus. Essa disputa é a principal responsável pelo surgimento de uma nova modalidade nas relações internacionais no início do século XX, pois é em seu bojo que nasce a política cultural internacional, uma espécie de quarta dimensão nas relações internacionais - sendo as outras três: a comercial, a militar e a política -, cujas funções primordiais são as de criar, ou desenvolver, no estrangeiro, a admiração pela cultura do país que a pratica, e, desse modo, incentivar a demanda por seus produtos, além de simpatias políticas em caso de necessidade.

A diferença essencial entre os conceitos de "ação cultural internacional» e «política cultural internacional» reside no fato de que a primeira ocorre de forma espontânea entre os povos e/ou como fruto de iniciativas privadas, enquanto a segunda é um apanágio do Estado. A referida distinção entre esses dois conceitos nos ajuda a melhor compreender a presença cultural francesa no Brasil; tanto é que podemos afirmar que até o começo do século XX ela se manifesta espontaneamente, mas, a partir dessa época, o Estado torna-se paulatinamente o principal tutor dos elementos culturais franceses exportados para o Brasil.

A França é geralmente vista como país pioneiro na política cultural internacional. Costuma-se definir a Aliança Francesa como embrião e marco histórico desse gênero de política, mesmo tratando-se de uma instituição privada. Fundada em Paris em 1883 por um grupo de intelectuais, religiosos e políticos de alto escalão, essa associação foi reconhecida como de utilidade pública pelo Estado, em 1886. Em seu primeiro estatuto, de março de 1884, consta que a "Associação nacional [serve] à propagação da língua francesa nas colônias e no estrangeiro", e que, para esse fim, ela deve "fundar e subvencionar escolas francesas, ou introduzir cursos de francês no interior das escolas» (BRUEZIERE, 1983, p. 11).

Com o fim da Primeira Guerra e a consequente perda de hegemonia dos impérios francês e britânico, em função do surgimento dos EUA como principal 
potência política mundial, a França percebe a necessidade de fortalecer a sua presença cultural no estrangeiro, e assim, cria em 1920, junto ao seu Ministère des Affaires Etrangères (Ministério das Relações Exteriores), o Service des CEuvres Françaises à l'Etranger - SOFE (Serviço das Obras Francesas no Exterior).

No interior do SOFE, o Estado conta com uma verdadeira "tropa» de intelectuais, que têm como tarefa divulgar mundo afora as ciências, as letras, as filosofias e as artes do país, com o fim de criar demandas por produtos desenvolvidos pela indústria, pelas ciências e pela cultura francesa em geral.

\section{Política cultural francesa no Brasil}

O SOFE trabalha com especialistas nas diversas partes do mundo, e o grupo que deve definir e dirigir a política cultural a ser implantada na América Latina reúne personalidades, como George Dumas, Paul Rivet, Ernest Martinenche, etc. A ideia é a de criar relações de amizade com as elites da região, e a partir daí desenvolver os seus interesses. Por isso, a ênfase deve ser dada na formação das elites, desde a educação básica até a universidade; portanto, nos cursos de língua francesa e nos cursos universitários.

É a partir dessa matriz teórica, que George Dumas desenvolve as bases da política cultural francesa no Brasil. De 1920 a 1938, ele efetua 17 missões na América Latina, onde cria várias instituições, cabendo mencionar aqui somente as criadas no Brasil: em 1922, é fundado no Rio de Janeiro o Instituto de Alta Cultura Franco-Brasileiro; em 1923, a Sociedade dos Liceus FrancoBrasileiros (Liceu de São Paulo; sendo que o do Rio de Janeiro existe desde 1915); a partir de 1934, é organizada a primeira das cinco missões destinadas à fundação da Universidade de São Paulo, e, posteriormente, três missões para a Universidade do Distrito Federal, e, em seguida, duas missões para a Universidade do Brasil, e, finalmente, duas missões para a Universidade de Porto Alegre (SUPPO, 1998, p.130).

Comparativamente a outros países, a política cultural francesa aplicada no Brasil se desenvolve com relativa facilidade, pois diferentemente das outras nações, a França encontra aqui um secular «solo fértil». Mesmo que exista consenso entre os especialistas quanto à constatação do declínio da preponderância cultural francesa no país, desde o início do século XX, o fato é que os primeiros cinquenta anos da República brasileira são marcados por acontecimentos que continuam a testemunhar a relevante frequência da cultura francesa. Mencionamos aqui somente alguns dos mais significativos:

Pouco antes da República, em 1885, é criada a primeira Aliança Francesa no Brasil, no Rio de Janeiro; a fundação de Belo Horizonte em 1894 é resultado de um projeto ligado diretamente ao conceito de urbanismo francês; e as grandes reformas urbanas realizadas por Pereira Passos, no Rio de Janeiro, no primeiro decênio do século $X X$, preconizam traços similares aos criados pelo Barão Haussmann, em Paris, no final do século XIX. 
No domínio militar, o presidente Epitácio Pessoa, através de seu ministro da Guerra, projeta modernizar a organização das Forças Armadas, construindo casernas e criando escolas e serviços, em conformidade com o modelo francês. Para tanto, ele contrata uma missão militar francesa, a partir da qual "estabeleceu-se uma orientação doutrinária de base nas Forças Armadas Brasileiras» (TAVARES, 1979, p. 270), e foram criadas várias escolas-modelo: a Escola do Estado-Maior, a de Aperfeiçoamento de Oficiais e a Escola de Aviação do Campo dos Afonços, no Rio de Janeiro - tendo sido esta última realizada pelos próprios oficiais da missão francesa.

No domínio das artes, a influência francesa é relevante nesse período. O Movimento Modernista brasileiro, além das características nacionais, está diretamente ligado aos modernistas europeus, principalmente franceses, e à ebulição que ocorre na Paris da Belle époque e dos Années folles, em particular no que concerne à estética e às ideias que a guiam: valorização de "primitivismos», bem como da ingenuidade, pureza e infantilidade, e também do inconsciente.

\section{Segunda Guerra: duas Franças, duas imagens}

A partir da década de 1940, acentuam-se as mudanças no olhar do Brasil sobre a Europa e sobre si mesmo. Em decorrência das duas Grandes Guerras, ao mesmo tempo em que se constata a decadência dos velhos impérios, desenvolvese o orgulho nacional brasileiro.

Em 1939, o embaixador francês no Rio de Janeiro é pessimista quanto às comemorações dos 150 anos da Revolução Francesa no Brasil. Em carta enviada ao seu governo, ele esclarece que «existem poucas chances de que a sugestão [da França] de associar o governo [brasileiro às comemorações] encontre no Brasil uma boa acolhida na imprensa por três razões: o caráter resolutamente conservador e anti-liberal do Estado Novo, suas tendências nacionalistas e a posição de princípio que o governo brasileiro tem contra toda ideologia de origem estrangeira» (Citado por ROLLAND, 2000b, p. 315).

Realpolitik brasileira à parte, a ambígua imagem da França no Brasil, a partir do Armistício de 1940, é assimétrica; afinal, sua imagem tradicional, a secular, é a que fica selada na história das mentalidades. Portanto, durante longo período histórico, é ela que permanece, após a Segunda Guerra. Já a aliança franco-nazista está fadada à história política, portanto à de curta duração, pois os brasileiros sempre tiveram uma imagem idealizada da França, que, no início, acontecia de maneira espontânea, mas, a partir dos anos de 1920, é trabalhada pela política cultural francesa; para os brasileiros dos anos quarenta, Vichy representa um hiato na história da França no país.

No Brasil, ao menos até a ruptura com o Eixo, em 1942, a política cultural francesa é dirigida pela embaixada vichysta no Rio de Janeiro; o que mesmo assim não impede que se difunda, fora dos meios diplomáticos oficiais, a imagem da França resistente, a partir de Londres - uma situação assaz complexa, visto que 
a priori antagônicas, elas apresentam, em muitos momentos, a convergência de suas prioridades: um bom exemplo, neste sentido, é a defesa e o esforço em salvaguardar a imagem positiva do "gênio» francês, no domínio das artes e do pensamento - o que interessa evidentemente a vichystas e resistentes. A turnê teatral dirigida por Louis Jouvet (ator e diretor de teatro francês, dentre os mais reputados na época), no Rio de Janeiro, em 1941, é subvencionada pelo governo de Vichy, e se beneficia do apoio dos representantes da Resistência francesa no Brasil. Quanto ao referido diretor, cabe dizer que em suas numerosas conferências e entrevistas dadas no Brasil, ele jamais assumiu ser representante do governo de Vichy, ou simpatizante da Resistência, definindo-se, isso sim, como um porta-voz da arte teatral francesa (ROLLAND, 2000a).

Já no que se refere ao tabuleiro do jogo geopolítico internacional do pós-guerra, a importância econômica, bélica e política da França se reduz, e como a ela se atrelava sua relevância cultural, pode-se dizer que a preponderância da cultura francesa no Brasil passa a periclitar. Por outro lado, a sua relativa debilidade, nesses três níveis das relações internacionais, pode ser atenuada pela sua tradicional brilhante reputação cultural. Consciente desse fato, mais do que jamais em sua história, o Estado francês dispenderá um grande esforço em sua política cultural internacional.

\section{Presença cultural francesa no Brasil a partir de $1945^{*}$}

Ao contrário do que ocorreu com a França, a América Latina e, particularmente, o Brasil ganharam peso político com o fim da Segunda Guerra. Rapidamente os franceses constataram essa nova realidade, como nos mostra um trecho do plano - ultra secreto - da sua política cultural definida para a região, em 1947 : «Desde 1939, o Brasil [...] tem nitidamente se industrializado. Os recursos minerais, sobretudo em ferro, prometem ao Brasil um futuro industrial de primeiro plano [...] Todos (os países da América Latina) são representados na ONU, onde contam 20 votos sobre 51. Sem exagero, podemos dizer que nenhuma decisão importante pode ser tomada na Assembléia da ONU sem o acordo da América Latina. [...] Fazer desse continente, além de um grande lar da língua francesa, um centro de irradiação de nossas artes, ciências e idéias [...] seria dar à nossa cultura no mundo uma possibilidade de expansão infinitamente maior.

A decisão de adotar nas grandes conferências a língua francesa como língua de trabalho, em pé de igualdade com o inglês, e também de instalar em Paris a organização intelectual mundial (UNESCO), não seria possível sem o apoio das Repúblicas latino-americanas. Mesmo ao olhar das grandes potências, sobretudo os EUA, nossa posição pode ser infinitamente reforçada, se nós dispusermos de uma influência cultural sólida nessas Repúblicas» («Plan d'action pour l'Amérique Latine " (très confidentiel). Paris : DGRC, MAE, AMAE, 1947).

\footnotetext{
*Todas as citações a seguir referidas foram retiradas de minhas dissertações de mestrado e doutorado.
} 
A nova política cultural francesa para a América Latina começa a ser elaborada em 1945, a partir do relatório feito pela missão dirigida por Pasteur Vallery Radot e Raymond Ronze. Essa missão tem como função «avaliar a situação da imagem da França e suas instituições nos países latinos da América». Ela conclui que "a acolhida calorosa que a missão recebeu, s'explica pela afeição das nações latinoamericanas pela França e pelo desejo que elas têm em lutar contra a expansão intelectual dos EUA». (Rapport de la Mission en Amérique Latine. Paris: DGRC, MAE, AMAE, 01/07/1945).

Já em 1945, imediatamente após a Liberação, a França envia ao Brasil o seu primeiro attaché cultural (responsável junto à embaixada pela incrementação e organização dos acontecimentos culturais). No ano seguinte, ela organiza uma mega exposição no Rio de Janeiro para mostrar o que é a «Nova França», nos espaços do Museu de Belas Artes, do eminente prédio do Ministério da Educação (atual edifício Gustavo Capanema), e do Cassino de Copacabana. São expostos pinturas, esculturas, artes decorativas (cerâmicas, bijuterias, mobílias...), discos, livros e filmes; além de produtos, como vinhos, champanhe, perfumes, alta-costura, etc. Também foram planejados grandes consertos para Cassinos ou Music Hall, e, para fechar com chave de ouro, uma turnê da Comédia Francesa. (Carta do Embaixador d'Astier ao MAE. Rio, 30/03/1945. Service des CEuvres, MAE, AMAE).

\section{Expansão geográfica da política cultural francesa no Brasil}

Após a Segunda Guerra, acentuam-se as lutas por independência nas colônias da França, e como a Guiana Francesa tem fronteira com o Brasil (aliás, o Brasil é o país que tem a maior fronteira terrestre com a França: $730 \mathrm{~km}$ ), o Estado francês, através da sua política cultural, aumenta a subvenção na região norte do Brasil. O Colégio Notre Dame de Nazaré, em Belém do Pará, dirigido por uma congregação religiosa francesa, transforma-se em pequeno centro estratégico, onde os padres e missionários são aconselhados a inculcar nos estudantes uma consciência de grande admiração pela França metropolitana, ao mesmo tempo em que devem impedir que se desenvolva qualquer espécie de simpatia por movimentos separatistas que, por ventura, venham a ocorrer na vizinha Guiana Francesa (Nota interna da DGRC, MAE. Paris, 22/09/1948. AMAE). No outro extremo do país, a França também aumenta a sua atuação cultural, pois é no sul do Brasil que se concentram as colônias italiana e alemã; sem contar o fato de que a despeito do declínio que se seguiu à derrota na Segunda Guerra, a Alemanha sempre representara, durante a industrialização brasileira, um dos nossos principais parceiros comerciais.

Por outro lado, como o projeto elaborado para política cultural francesa possui como condição sine qua non para o seu êxito - a expansão da língua de Molière no país -, a educação recebe atenção particular. Assim, a França passa a ajudar financeiramente, e de modo sistemático, os colégios dirigidos por congregações religiosas de origem francesa (em 1946, existem 23 dessas congregações atuando 
por todo o Brasil). Além disso, como a cultura norte-americana, que atinge mais diretamente as massas, tornara-se, desde então, a principal concorrente da cultura francesa no Brasil, os franceses passam a se empenhar na criação de filiais da Aliança Francesa em todas as cidades importantes do país: em relatório interno do Ministère des Affaires Étrangères, de 1945, define-se que a Aliança Francesa no Brasil deve servir «como um grande centro de estudos, um lar de irradiação do pensamento francês, onde os futuros professores de língua devem estudar a história da arte francesa, das ciências, da geografia, etc.». Já no que se refere à difusão de revistas e livros franceses, o Ministério é taxativo (ao menos por um período): «Não se deve traduzi-los. Que os brasileiros se habituem novamente a ler em francês (em contraposição ao avanço da língua inglesa), que eles compreendam que, sabendo francês, todos os tesouros do espírito Ihes são abertos» (Carta da embaixada francesa no Rio à DGRC, MAE, 1945 (data ilegível). AMAE).

Essas informações contêm as razões pelas quais cresceu enormemente o esforço da política cultural francesa no Brasil, a partir de 1944. Se até esta data existem somente as unidades da Aliança Francesa do Rio, São Paulo, Curitiba e Porto Alegre (essas duas últimas criadas no final dos anos trinta, inclusive para se contrapor às línguas italiana e alemã), já no ano seguinte são criadas as de Belo Horizonte, Juiz de Fora, Fortaleza e Santos; e, posteriormente, as de Recife, Salvador, Belém, Natal, Florianópolis e Pelotas. Assim, em 1983, contam-se 31 Alianças no Brasil; algumas delas com várias filiais, como as do Rio de Janeiro com 6, e as de São Paulo com 8, contabilizando, à época, 34 mil estudantes em todo o Brasil.

A França também implanta dois importantes centros culturais, que fazem bastante sucesso entre as classes média e alta: no Rio de Janeiro, é criada a Maison de France, que tem o seu teatro inaugurado em 1956; e, em São Paulo, o Centro Cultural da Aliança Francesa abre as portas do seu teatro em 1963. Como o teatro francês sempre tivera excelente acolhida no Brasil (ao menos até os anos 1960), a França passa a enviar a cada dois anos, a partir de 1945, renomadas trupes teatrais em turnê por todo o país; sendo que entre 1960 e 1970, essas turnês tornam-se anuais. Além disso, desde a segunda metade dos anos 1950 e até os anos 1970, o Estado francês sustenta financeiramente dois grupos teatrais franco-brasileiros: Les Comédiens de l'Orangerie, instalados no Rio, e Les Strapontins, em São Paulo; ambos com sucesso de público e crítica durante os anos 1970.

É também importante lembrar que esses dois centros culturais, assim como as Alianças Francesas das outras capitais, possuem bibliotecas, discotecas, videotecas e salas de exibições de filmes, por meio das quais a França propagandeia a sua cultura literária, musical e cinematográfica.

Sempre com o intuito de incrementar a sua presença no meio acadêmico brasileiro, para através da elite intelectual e científica, canalizar aos outros grupos da sociedade a sua cultura, os franceses do pós-Guerra aumentam o número de bolsas de estudos para estudantes e pesquisadores brasileiros na França, empenhando-se em assegurar, para intelectuais e cientistas de seu país, postos de 
professores e pesquisadores nos centros de pesquisas e universidades brasileiras. Para esses mesmos fins, são assinados dois importantes acordos entre Brasil e França: o Acordo Cultural Franco-Brasileiro, em 1948, e em 1967, o Acordo de Cooperação técnica e científica entre a República Francesa e os Estados Unidos do Brasil. Cabe ainda lembrar a criação, em meados dos anos 1970, da Escola Francesa de Brasília, hoje Liceu François Mitterrand.

\section{Algumas considerações finais}

O mais importante a reter é o fato de que a presença cultural francesa no Brasil se desenvolve a partir do final do século XVIII, e avança de maneira espontânea até o início do século XX, sendo que principalmente a partir dos anos de 1920, o Estado francês passa a instrumentalizar a cultura do seu povo no Brasil.

O curioso nesse longo processo é constatar que a relevância da cultura francesa no Brasil diminui, principalmente a partir dos anos de 1960, na mesma medida em que o Estado francês passa a utilizá-la como instrumento da sua política internacional. Contudo, que fique claro que essa diminuição não tem nenhuma relação com a intervenção do Estado; aliás, não fosse por ele, a presença cultural francesa no Brasil provavelmente seria menor do que é hoje.

Siglas: AMAE: Archives du Ministère des Affaires Étrangères / DGRC: Direction Générale des Relations Culturelles / MAE: Ministère des Affaires Étrangères / SOFE: Service des CEuvres Françaises à l'Étranger.

\section{Referências}

BRAUDEL, Fernand. A dinâmica do capitalismo. Rio de Janeiro: Ed. Rocco, 1987.

BRUEZIERE, M. L'Alliance Française, histoire d'une institution. Paris: Hachette, 1983.

EDWALDO, Cafezeiro e GADELHA, Carmem. História do teatro brasileiro: Um percurso de Anchieta a Nelson Rodrigues. Rio de Janeiro: ADUERJ, UFRJ, FUNART, 1996.

ELIAS, Norbert. La civilisation des mœurs. Paris: Hachette, 1973.

IGLÉSIA, Francisco. Trajetória política do Brasil (1500-1964). São Paulo: Cia. das Letras, 1993.

RODRIGUES PEREIRA, Marcio. Histoire du théâtre français au Brésil, de 1945 à 1970. DEA

(dissertação de mestrado), Paris 4-Sorbonne, dir. Luíz Felipe de Alencastro, 2001.

RODRIGUES PEREIRA, Marcio. La politique culturelle française au Brésil de 1945 à 1970: Un défi au recul de l'influence culturelle de la France. Doutorado (em andamento), Université de Strasbourg 3, orientação de Denis Rolland.

INET, Jean François E. Notice sur l'œuvre et la vie d'Auguste Comte. Paris: Lib. Richelieu, 1864. ROLLAND, Denis. Louis Jouvet et le Théâtre de l'Athénée. Promeneur de rêves en guerre de la France au Brésil. Paris: L'Harmattan, 2000a.

ROLLAND, Denis. La crise du modèle français. Marianne et l'Amérique Latine. Culture, politique et identité. Rennes: Presses Universitaires de Rennes, 2000b.

SUPPO, Hugo Rogélio. Le Brésil pour la France... In: ROLLAND, Denis (org.). Le Brésil et le Monde. Pour une histoire des relations internationales des puissances émergentes. Paris: L'Harmattan, 1998.

TAVARES, Lyra. Brasil-França. Ao longo de cinco séculos. Rio de Janeiro: Biblioteca de Exército, 1979. ZWEIG, Stefan. Brésil, terre d'avenir. Paris: Éditions de l'Aube, 1992. 


\title{
RESUMO
}

A presença cultural francesa no Brasil se desenvolve no decorrer do século XIX e se estende, como cultura estrangeira preponderante na consciência da elite brasileira, até os anos de 1960, quando é suplantada pela avassaladora presença da cultura norte-americana e, antes disso, pelo nacionalismo brasileiro. Até o início do século XX, sua influência sobre a elite brasileira se faz de maneira espontânea, como consequência da dinâmica do capitalismo. Porém, desde os anos de 1920, ela se faz, em boa parte, em função da política cultural internacional do Estado francês.

Palavras-chave: Brasil; França; cultura.

\begin{abstract}
The French cultural presence in Brazil develops during the XIX ${ }^{\text {th }}$ century and extends, as dominating foreign culture in the consciousness of the Brazilian elite, until the years of 1960, when is supplanted by the strong North American cultural presence and before that for the Brazilian nationalism. Till the beginning of the $X X^{\text {th }}$ century, its influence on the Brazilian elite took place in a spontaneous way, as consequence of capitalism's dynamics. However, since twenties, it occurs, mainly due the French State's international cultural policy.
\end{abstract}

Keywords: Brazil; French; cultural. 